\title{
The Relation between Life Long Learning Tendency and Leadership Level of Education Managers
}

\author{
Ertuğrul ÇAM*,Fatih SALTAN and Recep ÇAKIR \\ Amasya University, Amasya, Turkey
}

\begin{abstract}
People strongly desire that their children attend to high quality schools. Teachers and administrators are the ones who create those high quality schools. Administrators who improve themselves, follow the latest developments, and wish to learn more affect teachers' performance; and by this way, the quality of the education will perceptibly increase. Effective administrators are very important factors at educational institutions to reach the goals. School administrators are at the forefront as leaders, so the characteristics of the administrators have great importance for good education. At educational institutions, teachers are the ones who are generally tried to be trained. However, the training of the administrators in terms of leadership in education is also essential. The need for learning is the first step of the administrators for their own development and the development of their schools. The purpose of this study is to investigate life long learning tendency, leadership level and whether there is a relation between them for education managers $(\mathrm{N}=135)$. This study is done by the help of 135 education managers in Bulanık town of Muş. Data is collected with ' Life Long Learning Tendency Test' by DikerCoşkun (2009) and 'Leadership Questionnaire' by NevinBayrak (2001). Data analysis is made with statistical data analysis packet program. According to the results of the analysis, there is no meaningful relation between life long learning tendency and leadership level.
\end{abstract}

Key words: Life long learning tendency, leadership level, education manager

\section{INTRODUCTION}

It is unquestionable that children are the future of the societies. As a result, people strongly desire that their children attend to high quality schools. Teachers and administrators are the ones who create those high quality schools. Administrators who improve themselves, follow the latest developments, and wish to learn more affect teachers' performance; and by this way, the quality of the education will perceptibly increase. Today, the rapidity of scientific, technological, and cultural developments and the continuity of the changes in knowledge make people feel the need for learning all the time. In addition, the competition environment available in today's world, moving effectiveness to the top is considered to be very important, so leadership has gained more significance in educational institutions. 
Effective administrators are very important factors at educational institutions to reach the goals. School administrators are at the forefront as leaders, so the characteristics of the administrators have great importance for good education. At educational institutions, teachers are the ones who are generally tried to be trained. However, the training of the administrators in terms of leadership in education is also essential. The need for learning is the first step of the administrators for their own development and the development of their schools. At this very moment, the lifelong learning of the educational administrators/leaders becomes a part. The aim of this study is to determine the relationship between the leadership level and the tendency for lifelong learning.

\section{Leadership}

There are a great number of descriptions of 'leadership' in literature. Erçetin stated that the perception of 'leadership' changes according to the positions, processes, and groups that the leader is present (as cited in Cemaloğlu,2007).Generally, leadership means the ability and the knowledge to gather a group to him within the scope of certain objectives, and to activate that group so as to reach those objectives. Some types of leadership are described below.

Educational Leadership:The most important distinctive feature of the educational leadership is its focus on learning and teaching processes (Gümüşeli, 1996). In other words, educational leadership is directly related to the student, teacher, and educational program.

Ethical Leadership:Ethic is a discipline that searches the acceptability of the values and rules which form the basis of individual and social relationships. A leader having the tendency for ethics gives importance to the evaluation of ethical behaviors of the personnel. Ugurlu\&Üstüner (2011) believe that most of the educational leaders are well equipped with true values and ethical rules.

Visionary Leadership: Vision reflects the future of an institution. Buluç (2009)states that the visionary leadership is the ability to create a vision that affects and activates people as a whole. Visionary leader has a different point of view in future and effectively communicates his vision to all personnel at the institution.

Transformational Leadership:Karip (1998)suggests that transformational leaders motivates the personnel intellectually and gives energy to them; increases their interest in the objectives by awakening their vision and mission conscious.

\section{LifeLong Learning}

People, today, feel the need for learn all the time because of the rapid changes in science, technology, culture, and knowledge. Being adapted to those changes, following the innovations, and pioneering the changes are the prior capabilities expected from people. These are not arbitrary applications, but compulsory. Especially rapid changes in education requires leaders to develop new leadership approaches, new visions and missions; and to use technology more effectively in education; and to learn all the time. Following the new teaching methods and techniques, and using educational technologies more effectively requires educators to be in the process of lifelong learning. Coşkun\&Demirel (2012) state that when the cognitive and affective characteristics of individuals who are lifelong learners are studied, concepts such as motivation, persistence, curiosity, and arranging learning come to 
the forefront. Motivation is the drive that activates the individual. A motivated individual needs persistence in learning. Another significant concept is curiosity in order to continue the lifelong learning because it constantly drives the individual into the motivation cycle.

\section{The Problem}

What is the relationship between the lifelong learning tendency of educational leaders and their leadership types like?

(1) What level of lifelong learning tendency do the educational administrators have?

(2) Which type of leadership and at what level do the educational administrators demonstrate?

(3) Does lifelong learningtendency change according to gender?

(4) Do leadership levels change according to gender?

(5) Is there a meaningful relationship between lifelong learning and leadership levels?

\section{The Purpose}

The purpose of the study is to determine the leadership levels, leadership characteristics (visionary, learning, educational, transformational, ethic), and lifelong learning tendencies of educational leaders; and to find out the relationship between the leadership level and lifelong learning tendency.

\section{METHOD}

This study aims to reveal the characteristics of educational leaders and their tendency to learn, and the relation between them. For this reason, the research design used here is the relational screening model that shows the present situation. "Relational screening models are research models that aim to determine the existence and/or the degree of covariance between two or more variables" (Karasar, 2012, p.81).

\section{Population}

135 educational administrators who work in Muş, Bulanık in 2014-2015 school year participated in this study.

\section{Sampling}

"Easily Accessible Situation Sampling" was used as a method because this sampling helps the researcher be faster and practical.

\section{Data Collection Tools}

Lifelong Learning Tendency Scale:In this study, 27-item "Lifelong Learning Tendency Scale" that was developed by Diker\&Coşkun (2009) and that have .890 internal coefficient of consistence was used. The sub-dimensions of the scale are constancy, motivation, deprivation of arranging learning, and deprivation of interest. 
Leadership Styles Scale: 44-item and 4 point likert type leadership questionnaire developed by Bayrak (2001) was used. The sub-dimensions of the scale are educational leadership, ethical leadership, visionary leadership, learning leadership, and transformational leadership.

\section{FINDINGS}

This part shows the findings gained from scales that were applied to educational administrators working in Bulanık, Muş in order to determine their lifelong learning tendency and leadership types. The participants' descriptive statistics; the variance of their lifelong learning tendencies and leadership types according to gender; and the relationship between lifelong learning tendency and leadership types arerespectively given below.

\section{The Descriptive Statistics of the Participants}

Table 1.Participant Educational Administrators' Gender

\begin{tabular}{lll}
\hline & Frequency & Percentage \\
\hline Male & 102 & 75,6 \\
Bayan & 33 & 24,4 \\
\hline Toplam & 135 & 100,0 \\
\hline
\end{tabular}

According to Table 1, 75,6 percent of the participants are male, while 24.4 percent of them are female administrators.

Table 2.The Leadership Years of the Participant Educational Administrators

According to Table 2, 40 percent of the participants have been working as educational administrators for 5 years and less; 46.7 percent of them for 6-10 years; and 13.3 percent of them for 11-15 years.

Table 3.Tests of Normality

\begin{tabular}{lllllll}
\hline & \multicolumn{5}{l}{ Kolmogorov-Smirnov } & \multicolumn{3}{l}{ Shapiro-Wilk } \\
\cline { 2 - 7 } & Statistics & SD & $\mathrm{p}$ & Statistics & SD & $\mathrm{p}$ \\
\hline Leadership &, 130 & 102 &, 000 &, 920 & 102 &, 000 \\
LifelongLearning &, 154 & 33 &, 045 &, 916 & 33 &, 014 \\
Tendency & & & & & & \\
\hline
\end{tabular}

In social sciences, study data showing normal division features means low probability. Tabachnick (2013) states that the division is considered to be normal when it has the skewness andkurtsosisvalues between -1.5 and +1.5 at the end of the tests applied to see whether the data shows normal division features. When the data division is considered to be

\begin{tabular}{lll}
\hline & Frequency & Percentage \\
\hline 5 year and less & 54 & 40,0 \\
6-10 years & 63 & 46,7 \\
$11-15$ years & 18 & 13,3 \\
\hline Total & 135 & 100,0 \\
\hline
\end{tabular}

normal, it is possible to apply parametric tests for the analysis. According to this inference, 
the data division is accepted to be normal in this study, and parametric tests are applied.

\section{The Lifelong Learning Tendencies of the Participant Educational Administrators}

Table 4.Lifelong Learning Tendencyand Sub-Dimensions

\begin{tabular}{llll}
\hline & Total Participants & $\begin{array}{c}\text { Mean } \\
\text { (Over 6) }\end{array}$ & $\begin{array}{l}\text { Standard } \\
\text { Deviation }\end{array}$ \\
\hline Mean LifelongLearningTendency & 135 & 3,7951 & 0,474 \\
\hline Constancy Extent & 135 & 4,2333 & 0,973 \\
Motivation Extent & 135 & 3,8444 & 0,885 \\
Deprivation of arranging learning & 135 & 3,3889 & 0,903 \\
Deprivation of interest & 135 & 3,7407 & 0,694 \\
\hline
\end{tabular}

According to Table 4, it is observed that the mean of the lifelong tendencies of the participants is 3.80. considering the sub-dimensions of lifelong learning tendencies, it is found out that the mean of constancy is 4.23 ; the mean of motivation is 3.84 ; the mean of the deprivation of arranging learning is 3.38; and the mean of deprivation of interest is 3.74.

\section{The Leadership Types of the Participant Educational Administrators}

Table 5.Leadership Types

\begin{tabular}{llll}
\hline & Total Participant & $\begin{array}{c}\text { Mean } \\
\text { (Over 4) }\end{array}$ & $\begin{array}{c}\text { Standard } \\
\text { Deviation }\end{array}$ \\
\hline Mean Leadership & 135 & 2,8397 & 0,312 \\
\hline Educational Leadership & 135 & 2,7744 & 0,415 \\
Ethic Leadership & 135 & 2,7556 & 0,423 \\
Visionary Leadership & 135 & 2,7714 & 0,462 \\
Learning Leadership & 135 & 2,8417 & 0,363 \\
Transformational Leadership & 135 & 3,0133 & 0,653 \\
\hline
\end{tabular}

According to Table 5, the mean of the leadership of the administrators is 2.83. When subdimensions are observed, it is seen that the mean of the educational leadership is 2.77 ; the mean of the ethic leadership is 2.75 ; the mean of the visionary leadership is 2.77 ; the mean of the learning leadership is 2.84; and the mean of the transformational leadership is 3.01.

\section{The Change of Lifelong Leaning Tendency According to Gender}

Table 6.The Difference of Lifelong Learning Tendency between Genders

\begin{tabular}{lllllll}
\hline Gender & $\mathrm{N}$ & Mean & Standard Deviation & SD & $\mathrm{t}$ & $\mathrm{p}$ \\
\hline Male & 102 & 3,7738 & 0,46981 & 133 & $-0,917$ & 0,361 \\
Female & 33 & 3,8608 & 0,48697 & & & \\
\hline
\end{tabular}

In order to find out whether lifelong learning tendency shows difference according to gender, independent sample $t$ analysis was done. The mean of the male participants tendency $(X=3,77)$ is lower than the the mean of the female participants' tendency $(X=3,86)$. However, this lowness is not statistically meaningful $(\mathrm{t}(133=-0,917 ; \mathrm{p}>0,05)$. 


\section{The Change of the Leadership Level According to Gender}

Table 7.The Difference of Leadership Levels between Genders

\begin{tabular}{cllllll}
\hline Gender & $\mathrm{N}$ & Mean & Standard Deviation & SD & t & $\mathrm{p}$ \\
\hline Male & 102 & 2,8644 &, 32008 & 133 & 1,627 & 0,106 \\
Female & 33 & 2,7633 &, 27574 & & & \\
\hline
\end{tabular}

In order to find out whether leadership levels show difference according to gender, independent sample $\mathrm{t}$ analysis was done. According to the results, the mean of the male participants' leadership level $(\mathrm{X}=2,86)$ is higher than the mean of the female participants' leadership level $(X=2,76)$. However, this highness is not statistically meaningful $(\mathrm{t}(133=1,627 ; \mathrm{p}>0,05)$.

\section{The ANOVA Results of Leadership Levels According to Leadership Year}

Table 8.The ANOVA Results of Leadership Levels According to Leadership Year

\begin{tabular}{llll}
\hline Leadership Year & $\mathrm{N}$ & Mean & $\begin{array}{l}\text { Standard } \\
\text { Deviation }\end{array}$ \\
\hline 5 years and less & 54 & 2,77 &, 46 \\
6-10 years & 63 & 2,88 &, 11 \\
11-15 years & 18 & 2,92 &, 16 \\
\hline Total & 135 & 2,84 &, 31 \\
\hline
\end{tabular}

\begin{tabular}{clllll}
\hline & Sum of Squares & SD & Mean of Squares & F & $\mathrm{p}$ \\
\hline Intergroup &, 460 & 2 &, 230 & 2,417 &, 093 \\
Intra-group & 12,575 & 132 &, 095 & & \\
\hline Total & 13,035 & 134 & & & \\
\hline
\end{tabular}

According to Table 8, leaders working for 5 years and less have the lowest mean $(X=2,77)$. With the mean of $(\mathrm{X}=2,88)$ leaders working for 6-10 years and with the mean of $(\mathrm{X}=2,92)$ leaders working for 11-15 yearscome after. ANOVA results show that the participants' leadership years and leadership levels do not have a meaningful difference $(F(2,132)=2,417 ; p>0,05)$.

\section{The ANOVA Results of Lifelong Learning Tendency According to Leadership Year}

Table 9.The ANOVA Results of Lifelong Learning Tendency According to Leadership Year

\begin{tabular}{llll}
\hline Leadership year & $\mathrm{N}$ & Mean & $\begin{array}{l}\text { Standard } \\
\text { Deviation }\end{array}$ \\
\hline 5 years and less & 54 & 3,72 &, 15 \\
6-10 years & 63 & 3,71 &, 60 \\
11-15 years & 18 & 4,28 &, 29 \\
\hline Total & 135 & 3,80 &, 47 \\
\hline
\end{tabular}

\begin{tabular}{llllll}
\hline & Sum of Squares & SD & Mean of Squares & F & p \\
\hline Intergroup & 4,84 & 2 & 2,42 & 12,66 &, 000 \\
Intra-Group & 25,231 & 132 &, 19 & & \\
\hline Total & 30,071 & 134 & & & \\
\hline
\end{tabular}

According to Table 9, leaders working for 6-10 years have the lowest mean (X=3,71).With the mean of $(X=3,72)$ leaders working for 5 years and less and with the mean of $(X=4,28)$ 
leaders working for 11-15 yearscome after. ANOVA results show that the participants' leadership years and lifelong learning tendency do not have a meaningful difference $(F(2,132)=12,66 ; p<0,05)$.

\section{Post Hoc Tests}

Table.10 The Difference of Lifelong Learning Tendency and Leadership Year

\begin{tabular}{lllll} 
(I) Leadership Year & (J) Leadership Year & & & \\
& & Mean Difference (I-J) & Standard Error & P \\
\hline 5 years and less & 6-10 years &, 00265 &, 07889 & 1,000 \\
& 11-15 years &,$- 55556^{*}$ &, 07061 &, 000 \\
\hline 6-10 years & 5 years and less &,- 00265 &, 07889 & 1,000 \\
& 11-15 years &,$- 55820^{*}$ &, 10157 &, 000 \\
\hline 11-15 years & 5 years and less &, $55556^{*}$ &, 07061 &, 000 \\
& 6-10 years &, $55820^{*}$ &, 10157 &, 000 \\
\hline
\end{tabular}

According to the results of the Post Hoc Test, there is a meaningful relationship between 5 years and less group and 11-15 years group on behalf of 11-15 years group. In addition, there is a meaningful difference between 6-10 years group and 11-15 years group on behalf of 1115 years group.

\section{The Relation Between Leadership Level and Lifelong Learning Tendency}

Table 11.The Relation Between Leadership Level and Lifelong Learning Tendency

\begin{tabular}{lllll}
\hline & & Leadership Level & $\begin{array}{l}\text { Lifelong } \\
\text { Tendency }\end{array}$ & Learning \\
\hline Leadership Level & Pearson & Correlation & 1 &,- 163 \\
& Coefficient & &, 059 \\
& P & & 135 \\
\hline Lifelong Learning Tendency & Number of Participant & 135 & 1 \\
& Pearson Correlation &,- 163 & \\
& Coefficient & & \\
& P &, 059 & 135 \\
\hline
\end{tabular}

There is no meaningful relation between the leadership features and lifelong learning tendency of the educational administrators (Correlation coefficient $=-0,163, p>0,05$ ). No changes occur in lifelong learning tendency when leadership level increases.

\section{RESULTS AND DISCUSSION}

Examining the means of the lifelong learning tendency scale, it was observed that lifelong learning tendency of educational administrators is not very high (Table 4). In contrast to previous research results, lifelong learning tendencies are higher. Similarly, Coşkun (2009), in her study conducted with university students, found out that lifelong learning tendency of the university students is low. However, Gencel (2013) revealed a reverse situation in her study conducted to determine the lifelong learning tendency of candidate teachers. In that study, it was found out that candidate teachers feel competent enough in terms of lifelong learning.

The lifelong learning tendencies of educational administrators are not at a sufficient level. Educational administrators will transfer the lifelong learning skill to teachers, and teachers will transfer it to students, so having the knowledge of educational administrators' lifelong 
learning tendencies becomes significant.

People having the competency of leadership can motivate others so as to achieve certain goals. The role of leaders is very important in encouraging people in lifelong learning. Especially, educational administrators' efforts will reach to students and the society will be up skilled. Considering the research results, it can be stated that leadership level of educational leaders is not high. Research results also revealed that gender differences did not affect the leadership levels. Another result was that lifelong learning tendency is higher in the group of participants who had 11-15 year experience in leadership, which can show that the need for learning arises after a certain age and experience.

Examining the sub-dimensions of leadership, educational leaders showed the characteristics of a transformational leader most. Buluç (2009) suggests that transformational leaders are the agent of change. Transformational leaders are seen as different characters showing similarities.

In addition, when the relationship between the leadership levels and lifelong learning tendency was analyzed, no meaningful relation was found. This study was expected to show that when leadership level increases, lifelong learning tendency will also increase because the sub-dimensions of the leadership level is visionary leadership, transformational leadership, educational leadership, and ethic leadership. It is thought that having a vision and being transformational and educational is always related to being up-to-date. Lifelong learning is necessary for being up-to-date.

Despite all these expectations, it is thought-provoking that there is no meaningful relationship between leadership level and lifelong learning tendency. As a result, besides lifelong learning tendencies and leadership levels, different situations of educational administrators can be studied. For instance, the effects of educational leaders' level of burnout, difficulties they encounter, and different variables on their leadership level and lifelong learning tendency can be examined.

\section{REFERENCES}

B.G. Tabachnick, L. F. (2013). Using Multivariate Statistics (sixth ed.). Boston : Pearson.

Buluç, B. (2009). The Relationships between Organizational Commitment and Leadership Styles of Principals Based on Elementary School Teacher's Perceptions . Theory and

Practice in Educational Administration, 5-34.

Buluç, B. (2009). The Relationships between Organizational Commitment and Leadership Styles of Principals Based on Elementary School Teacher's Perceptions. Theory and

Practice in Educational Administration, 5-34.

Cemaloğlu, N. (2007). Examining the different variables of Leadership Styles of School

Administrators.Turkish Journal of Educational Sciences, 73-112.

Coşkun, Y. D., \& Demirel, M. (2012). Lifelong Learning Trends of University Students. Journal of Hacettepe Faculty of Education, 108-120.

Çelik, V. (1998). Transformational Leadership in Education

Gencel, İ. E. (2013). Perceptions Towards Lifelong Learning Competencies of Teachers . Education and Science, 237-252. 
Uğurlu, C. T., \& Üstüner, M. (2011). Effects of Administrators' Ethical Leadership and Organizational Justice Behavior on Teachers' Organizational Commitment Level. Journal of Hacettepe Faculty of Education , 434-448. 